\title{
Investigation of methicillin-resistant Staphylococcus aureus among clinical isolates from humans and animals by culture methods and multiplex PCR
}

M. M. Rahman ${ }^{1,4+}$, K. B. Amin ${ }^{2 \dagger}$, S. M. M. Rahman³, A. Khair ${ }^{1}$, M. Rahman², A. Hossain ${ }^{3}$, A. K. M. A. Rahman', M. S. Parvez ${ }^{2}$, N. Miura $^{4 *}$ and M. M. Alam $^{1 *}$ (D)

\begin{abstract}
Background: Staphylococcus aureus is responsible for large numbers of hospital-related and community-acquired infections. In this study, we investigated the presence of S. aureus and methicillin-resistant S. aureus (MRSA) in 100 samples from animals (55 cattle, 36 dogs, and 9 cats) and 150 samples from hospitalized human patients. The samples were collected from healthy and diseased animals and from diseased humans and included milk, wound swab, pus, exudates, nasal swab and diabetic ulcer. Initially, S. aureus was isolated and identified by colony morphology, Gram staining, and biochemical tests (catalase and coagulase tests). The S. aureus-positive samples were examined by polymerase chain reaction (PCR) to determine their MRSA status.

Results: Of the 100 animal samples, 29 were positive for S. aureus. Four samples (13.8\%) from dogs were MRSApositive, but samples from cattle and cats were MRSA-negative. Of the 150 human samples we collected, 64 were $S$. aureus-positive and, of these, 34 (53.1\%) were MRSA-positive. Most (28\%) of the MRSA samples were isolated from surgical wound swabs, followed by the pus from skin infections (11\%), exudates from diabetic ulcers (6\%), exudates from burns (4\%), and aural swabs (3\%). By contrast, a low MRSA detection rate $(n=4)$ was seen in the non-human isolates, where all MRSA bacteria were isolated from nasal swabs from dogs. The antimicrobials susceptibility testing results showed that S. aureus isolates with mecA genes showed resistance to penicillin (100\%), oxacillin (100\%), erythromycin (73.5\%), ciprofloxacin (70.6\%), and gentamicin (67.7\%). The lowest resistance was found against ceftazidime, and no vancomycin-resistant isolates were obtained.

Conclusions: We detected S. aureus and MRSA in both human and canine specimens. Isolates were found to be resistant to some of the antimicrobials available locally. MRSA carriage in humans and animals appears to be a great threat to effective antimicrobials treatment. The prudent use of antimicrobials will reduce the antimicrobial resistance. Our findings will help to find the most appropriate treatment and to reduce antimicrobial resistance in the future by implementing prudent use of antimicrobials. Further studies are required to better understand the epidemiology of MRSA human-animal inter-species transmission in Bangladesh.
\end{abstract}

Keywords: Staphylococcus aureus, MRSA, Animals, Humans, Bangladesh

\footnotetext{
* Correspondence: k9236024@kadai.jp; asamahbub2003@yahoo.com

${ }^{\dagger}$ M. M. Rahman and K. B. Amin contributed equally to this work.

${ }^{4}$ Veterinary Teaching Hospital, Joint Faculty of Veterinary Medicine,

Kagoshima University, Kagoshima, Japan

'Department of Medicine, Faculty of Veterinary Science, Bangladesh

Agricultural University, Mymensingh 2202, Bangladesh

Full list of author information is available at the end of the article
}

(c) The Author(s). 2018 Open Access This article is distributed under the terms of the Creative Commons Attribution 4.0 International License (http://creativecommons.org/licenses/by/4.0/), which permits unrestricted use, distribution, and reproduction in any medium, provided you give appropriate credit to the original author(s) and the source, provide a link to the Creative Commons license, and indicate if changes were made. The Creative Commons Public Domain Dedication waiver (http://creativecommons.org/publicdomain/zero/1.0/) applies to the data made available in this article, unless otherwise stated. 


\section{Background}

Staphylococcus aureus is a leading cause of human nosocomial and community-acquired infections worldwide. Methicillin-resistant $S$. aureus (MRSA) isolates were first identified a few years after the introduction of methicillin in the 1950s following its application in the treatment of penicillin-resistant staphylococcal infections [1, 2]. Since then, MRSA has become recognized as a major health problem in human medicine internationally, especially in hospital settings [3]. Healthcare-associated MRSA (HA-MRSA) causes skin and soft tissue infection like sepsis, septic arthritis, pneumonia etc. [4] whereas community-associated MRSA (CA-MRSA) cause more deadly infection [5] and livestock-associated MRSA (LA-MRSA) are major reservoir of infection [6]. For almost four decades, the increasing prevalence of MRSA strains has posed a major clinical threat to worldwide public health and a significant challenge to the control of infection in human medicine [7].

With the growing prevalence of CA-MRSA [8], the epidemiological aspects of nosocomial infection are also being increasingly studied $[9,10]$. Several studies reported that healthy and disease animals usually cow, horses and companion animals can transmit this superbug to human and vice versa [11-14]. Others studies also indicated that companion or pet animals are responsible for household MRSA transmission and may serve as reservoir $[6,15]$.

Introduced in 1959, methicillin (methicillin, oxacillin, cloxacillin, and flucloxacillin) was the first introduced antimicrobial of the beta-lactam class that is resistant to beta-lactamase inactivation, and it was applied in the treatment of penicillin-resistant $S$. aureus. It is still used as a first-line treatment today, despite the first case of MRSA being reported in England [16] within 2 years of its clinical introduction. MRSA bacteria have developed resistance to all penicillins, including methicillin and other narrow-spectrum $\beta$-lactamase penicillin antibiotics [17]. Worldwide, about 2 billion people are carriers of $S$. aureus, and of these, it is likely that 53 million (2.7\% of carriers) carry MRSA. Furthermore, an animal-associated clone has been isolated from a human infection [18].

The chromosomally located mecA gene encodes the low affinity penicillin-binding protein 2a (PBP-2a) [19] in the presence of high concentrations of $\beta$-lactam antibiotics, which can function as a surrogate trans-peptidase capable of ameliorating the four high-affinity PBPs native to $S$. aureus [20]. PBP2 (PBP-2a), constitutively produced in some MRSA isolates; is the main mechanism of resistance [21-23].

In Bangladesh, the prevalence of MRSA in humans has been studied [24] and a recent report provided data on the prevalence of MRSA among dogs and cats in one particular city [25]. In the current study, we determined the prevalence of $S$. aureus isolates including MRSA in a convenience sample collected from hospitals and veterinary centers in selected areas of Bangladesh.

\section{Methods \\ Study period and place}

This study was conducted over a 1-year period from September 2013 to August 2014 at the Department of Medicine, Bangladesh Agricultural University (BAU), Mymensingh, Bangladesh, and Mymensingh Medical College, Mymensingh, Bangladesh.

\section{Sample collection}

A total of 100 samples from animals (55 cattle, 36 dogs, and 9 cats) were collected from the BAU Veterinary Clinic, smallholder dairy farms near the BAU campus, and from the Veterinary Hospital in Mymensingh Sadar and the Central Veterinary Hospital in Dhaka. A total of 150 human samples were collected from the Mymensingh Medical College Hospital, Mymensingh, Bangladesh.

Sterilized cotton swab sticks were used to collect samples of pus, mastitic milk, and wound infections. Nasal swabs were collected from normal dogs and cats without any signs of infection. The human sample compositions from hospitalized patients were as follows: surgical wound swabs $(n=95)$, pus from skin infections $(n=19)$, exudates from diabetic ulcers $(n=14)$, exudates from burns swabs $(n=13)$ and aural swabs $(n=9)$.

\section{Isolation and identification of S. aureus}

Bacteria were isolated and identified by their colony morphology, Gram stain results, and biochemical test results (catalase and coagulase tests) according to the report by Quinn and colleagues [26].

\section{Antimicrobial susceptibility testing}

Antimicrobial susceptibility testing was performed using the antimicrobial disc method recommended by the Clinical \& Laboratory Standards Institute (CLSI) (www.clsi.org). Seven antimicrobial agents were used to determine the antibiogram of the isolated organisms according to the Gram-positive panel of antimicrobials recommended by the CLSI. The antimicrobial panel comprised: penicillin (10 unit), oxacillin (1 $\mu \mathrm{g})$, erythromycin $(15 \mu \mathrm{g})$, ceftazidime $(30 \mu \mathrm{g})$, gentamicin $(10 \mu \mathrm{g})$, ciprofloxacin $(10 \mu \mathrm{g})$, and vancomycin $(30 \mu \mathrm{g})$.All of the $S$. aureus isolates were tested for their antimicrobial susceptibilities using the Kirby-Bauer disk diffusion technique according to the CLSI 2010 recommendations. All tests were performed using Muller-Hinton agar following $0.5 \mathrm{McFarland}$ standards $\left(1.5 \times 10^{8}\right)$. To standardize the disk potency, a representative disc was tested against the S. aureus ATCC 25923 reference strain. The zone of inhibition was compared with the standard value recommended by the CLSI. The results were interpreted as 
follows: zone of inhibition $\geq 13 \mathrm{~mm}=$ sensitive; zone of inhibition $\leq 10 \mathrm{~mm}=$ resistant.

\section{Bacterial genomic DNA extraction}

The boiling method was used to extract genomic DNA from the isolates [27]. Briefly, a single S. aureus colony was inoculated into $100 \mu \mathrm{l}$ of distilled water in an eppendorf tube, mixed well, and then boiled for $10 \mathrm{~min}$. After boiling, the tubes were immediately put on ice and then centrifuged at $9000 \times g$ for $10 \mathrm{~min}$ at $4{ }^{\circ} \mathrm{C}$. The bacterial DNA-containing supernatant was collected and used as a DNA template for multiplex PCR.

\section{Amplification of genus- and species-specific S. aureus genes}

Methicillin-resistant staphylococci were identified by PCR amplification of the mecA gene. DNA was extracted from $S$. aureus cultures and amplified with primers for the targeted Staphylococcus genus-specific 16S rRNA gene, the staphylococcus species-specific nuc gene, and the MRSA-specific mecA gene.

PCRs were performed in a gradient thermal cycler (Eppendorf, Hamburg, Germany). The S. aureus-specific nuc gene (279 bp), methicillin resistance mecA gene (147 bp), and Staphylococcus genus-specific 16S rRNA gene (756 bp) were detected. Previously reported primers were used, along with Staphylococcus genus-specific 16S rRNA (756 bp) as an internal control [28]. Each 25- $\mu$ l reaction mixture contained $5 \mu$ lof genomic DNA, $12.5 \mu \mathrm{l}$ of PCR master mix (Promega Corporation, Madison, WI, USA), $1 \mu \mathrm{l}$ of $100 \mathrm{pmol}$ of the forward and reverse primers, and the final volume was adjusted to $25 \mu \mathrm{l}$ with $5.5 \mu \mathrm{l}$ of nuclease-free water. DNA amplification involved denaturation at $94{ }^{\circ} \mathrm{C}$ for $1 \mathrm{~min}$, followed by 30 cycles at $94{ }^{\circ} \mathrm{C}$ for $30 \mathrm{~s}, 55^{\circ} \mathrm{C}$ for $30 \mathrm{~s}$, and $72{ }^{\circ} \mathrm{C}$ for $1 \mathrm{~min}$, with a final elongation step at $72{ }^{\circ} \mathrm{C}$ for $5 \mathrm{~min}$. The PCR products were analyzed by $1 \%$ agarose gel electrophoresis (Alpha Imager, Wiesbaden Germany), with ethidium bromide staining, and a gel documentation system (Alpha Imager) was used for photography.

\section{Documentation and visualization of DNA samples}

Following electrophoresis, PCR products were visualized using a UV transilluminator. Bands of $157 \mathrm{bp}$ (mecA), 297 bp (nuc), and 756 bp (16S rRNA) indicated positive results.

\section{Results}

A total of 100 samples from animals (cattle: 55, dogs: 36, cats: 9) (Table 1) and 150 samples from humans were included in this study (Table 2). Of these100 samples of animal origin, 29 were positive for $S$. aureus among the different animals. Among these 29 samples, four from
Table 1 Detection of S. aureus and MRSA among specimens from different animals sampled from September, 2013 to August, 2014

\begin{tabular}{llll}
\hline Animal & No. tested & $\begin{array}{l}\text { S. aureus } \\
\text { positive (\%) }\end{array}$ & $\begin{array}{l}\text { MRSA } \\
\text { positive (\%) }\end{array}$ \\
\hline $\begin{array}{l}\text { Cattle (Mastitic milk, pus } \\
\text { and wound swab) }\end{array}$ & 55 & $18(32.7)$ & - \\
Dog (Nasal Swab) & 36 & $09(25.0)$ & $04(44.4)$ \\
Cat (Nasal Swab) & 09 & $02(22.2)$ & - \\
Total & 100 & $29(29.0)$ & $04(13.8)$ \\
\hline 49. - Not detected & & &
\end{tabular}

dogs were MRSA-positive, while those from cattle and cats were MRSA-negative.

The samples from humans were collected from hospitalized patients. Of the 150 samples, 64 were S. aureus-positive. Among these 64, 34 were found to be positive for MRSA of human origin (Table 2). The growth characteristics, staining, and coagulase test results were all consistent with $S$. aureus. We confirmed the presence of the mecA (147 bp), nuc (279 bp), and 16S rRNA genes by multiplex PCR (Fig. 1).

Antimicrobial susceptibility testing of the isolated organisms with an antimicrobial panel was performed by the disk diffusion method using the Kirby-Bauer technique according to the CLSI 2010 guidelines. All of the tests were performed on Muller-Hinton agar. Seven antimicrobial agents were used to determine the antibiogram of the isolated organisms according to the Gram-positive panel of antimicrobials (penicillin, gentamicin, oxacillin, erythromycin, vancomycin, ciprofloxacin, ceftazidime) recommended by the CLSI. Plates were incubated at $35{ }^{\circ} \mathrm{C}$ for $24 \mathrm{~h}$, after which the inhibition zone was measured. The patterns of antimicrobial resistance among the isolates typed as MRSA are shown in Table 3. All 34 isolates were resistant to penicillin and oxacillin, and susceptible to vancomycin.

\section{Discussion}

After the introduction of $\beta$-lactam antimicrobials, the prevalence of MRSA infections and colonization increased

Table 2 Detection of S. aureus and MRSA among various specimens from humans sampled from September, 2013 to August, 2014

\begin{tabular}{llll}
\hline Types of specimens & No. tested & $\begin{array}{l}\text { S. aureus } \\
\text { positive (\%) }\end{array}$ & $\begin{array}{l}\text { MRSA } \\
\text { positive (\%) }\end{array}$ \\
\hline Surgical wound swab & 95 & $34(35.8)$ & $18(52.9)$ \\
Pus from skin infection & 19 & $11(57.9)$ & $7(63.6)$ \\
Exudates from diabetic ulcer & 14 & $07(50.0)$ & $4(57.1)$ \\
Exudates from burn & 13 & $07(53.8)$ & $3(42.9)$ \\
Aural swab & 9 & $05(55.6)$ & $2(40.0)$ \\
Total & 150 & $64(42.7)$ & $34(53.1)$ \\
\hline
\end{tabular}




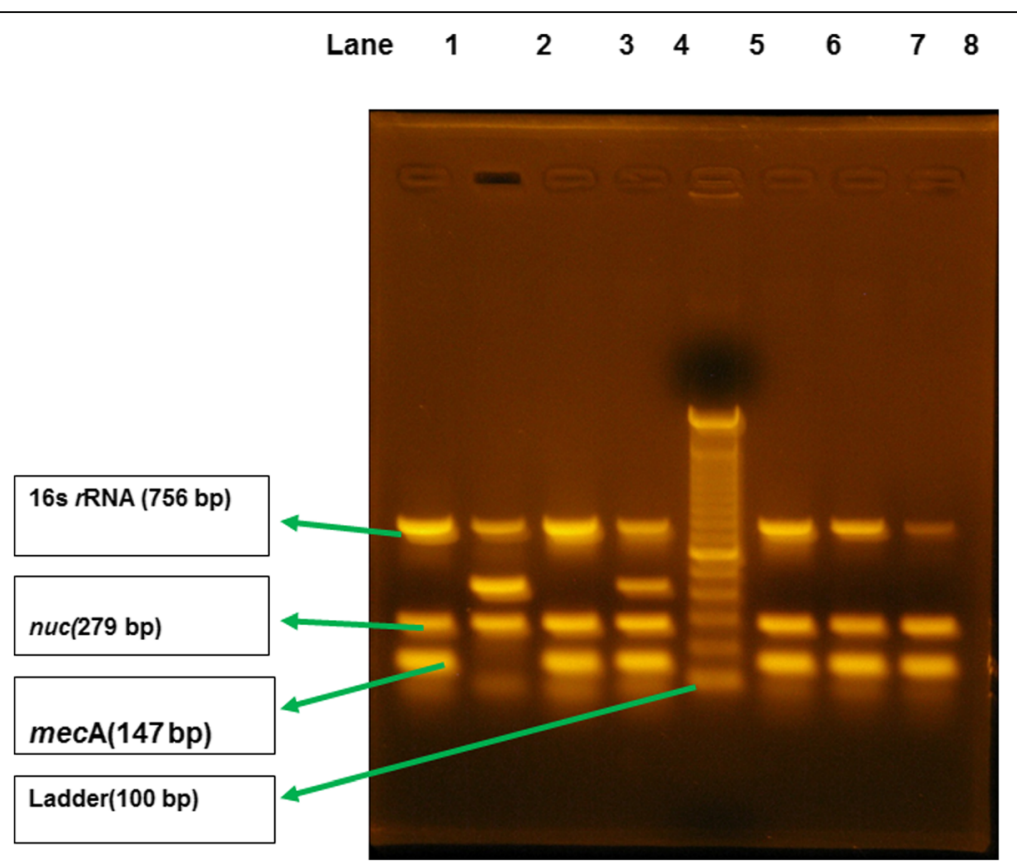

Fig. 1 Multiplex PCR assay to identify mecA (157 bp), nuc (297 bp), and 16S rRNA genes (756 bp) in S. aureus

steadily over time [27, 29]. Careful monitoring of the occurrence of MRSA is important for appropriate clinical management of hospital patients and for studying MRSA epidemiology in the community. In the present study, the prevalence of staphylococci (S. aureus) was 25\% among dogs, which was lower than two previous studies, $91 \%$ [30] and 65.1\% [31], among dogs in a referral animal hospital in the UK. However, those studies used samples from a limited number of hospitalized dogs and more than one sampling site. By contrast, the present study investigated the prevalence of MRSA in a larger vet-visiting dog community and omitted hospitalized dogs, which may be more representative of the healthy dog population in Bangladesh. Few studies have reported the overall prevalence of $S$. aureus, so it is not possible to draw

Table 3 Frequency of drug resistance in MRSA from animals and humans from September 2013 to August, 2014

\begin{tabular}{|c|c|c|c|c|}
\hline \multirow[t]{2}{*}{ Antimicrobials } & \multicolumn{2}{|l|}{ Humans } & \multicolumn{2}{|l|}{ Animal } \\
\hline & $\begin{array}{l}\text { No. of MRSA } \\
\text { isolates }(n=34)\end{array}$ & $\begin{array}{l}\% \text { of resistant } \\
\text { isolates }\end{array}$ & $\begin{array}{l}\text { No. of MRSA } \\
\text { isolates }(n=4)\end{array}$ & $\begin{array}{l}\% \text { of } \\
\text { resistant } \\
\text { isolates }\end{array}$ \\
\hline Penicillin & 34 & 100 & - & - \\
\hline Oxacillin & 34 & 100 & 4 & 100 \\
\hline Erythromycin & 25 & 73 & - & - \\
\hline Ciprofloxacin & 24 & 70 & - & - \\
\hline Gentamicin & 23 & 67 & - & - \\
\hline Ceftazidime & 21 & 61 & - & - \\
\hline Vancomycin & - & - & - & - \\
\hline
\end{tabular}

comparisons between different populations and countries. The present study showed that staphylococci carriage is not unusual in the nasal mucosa of dogs in Bangladesh. Although the proportion of isolated staphylococci was low in our study, the prevalence of MRSA was $11.1 \%$ among the dog population studied. Another recent study reported MRSA among dogs in Bangladesh [25], specifically MRSA was detected from nasal swabs, which was consistent with our study; however, their report was limited to a small confined area and included healthy and diseased dogs. Three other previous studies reported MRSA detection rates of $5 \%, 8 \%$, and $21.4 \%$ among the dog population in Jordan, Finland, and France, respectively [32-34]. Most importantly, other studies have also reported that canine MRSA strains reflect those prevalent in human hospital settings [35-37]. However, wounds are the major site of infection for MRSA in dogs, cats, and horses [38, 39], but all of the MRSA-positive samples were from nasal swabs. It is unclear to what extent MRSA carried in dogs is a potential source of transmission to humans and vice versa. MRSA among dairy cattle has been reported elsewhere $[6,12]$. The classes of antimicrobials commonly used in Bangladesh include penicillins, fluroquinolones, sulfonamides, tetracyclines, and aminoglycosides. Among these, tetracyclines are the most frequently used class of antimicrobials [40] which might be one of the causes why no MRSA was found in cattle. Our investigation revealed an overall prevalence of MRSA of $53.1 \%$ for the $S$. aureus samples from humans which was slightly higher than Khan and coworker's study [24] in Bangladesh. The prevalence of human MRSA in our study 
was also similar to that reported in studies from more developed countries such as Japan (52\%) [41] and the USA (54\%) [42]. There was no correlation between our study findings and those of a previous Bangladeshi study by Jinnah and colleagues where the occurrence of MRSA was reported to be $21.6 \%$ [43]. The occurrence of MRSA for humans in our study was also dissimilar to that of an Indian study (8\%) [44].

A significant increase in the prevalence of MRSA among the Bangladeshi population was reported in a previous study [45], which noted an increase in prevalence over time. This may be due to the widespread, excessive use of antimicrobials over recent years. The aim of the present study was to determine the rate of MRSA-positivity among isolates from patients and animals. We have shown that $n u c$ and mecA gene amplification by multiplex PCR as an efficient and rapid method to detect and identify MRSA from cultured specimens. Adopting this method may provide substantial benefits for infection control by allowing for precise and cost-effective control measures to be implemented. Our results showed that MRSA carriage among humans and animals threatens the effective antimicrobial treatment of infections with this bacterium, and the widespread use of antimicrobials may increase the risk of resistance gradually arising [46]. Consistent with our findings, macrolide and ciprofloxacin resistance was previously reported in MRSA $[47,48]$. Further studies on the distribution and persistence of MRSA strain reservoirs among animals and humans along with specific resistance patterns are now required.

Our study had some limitations that are worth noting. Domestic animals were only tested in urban areas, and many pet owners were reluctant to provide samples from their animals. This bacterium has public health implications for the owners since they might be infected with the same strains. As a result, it was difficult to obtain a representative number of samples to analyze. In future studies, further molecular characterization is needed to investigate the transmission of MRSA from animal species to humans by analyzing the genetic relatedness of the prevalent strains in humans and domestic animals in Bangladesh.

\section{Conclusions}

We detected S. aureus and MRSA in both humans and dogs. Some isolates were found to be resistant to antimicrobials available locally in Bangladesh. MRSA carriage in humans and animals appears to be a great threat to effective antimicrobial treatment. Therefore, our findings will encourage clinicians and health care institutions to adopt precise guidelines about the use of antimicrobials regarding MRSA patient treatment. Further studies are required to better understand the epidemiology of MRSA human-animal inter-species transmission.

\section{Additional files}

Additional file 1: Data on clinical samples from humans used for the detection of Staphylococcus aureus and MRSA in Bangladesh. (CSV 7 kb)

Additional file 2: Data on clinical samples from animals used for the detection of Staphylococcus aureus and MRSA in Bangladesh. (CSV 11 kb)

\section{Abbreviations}

CLSI: Clinical and Laboratory Standards Institute; MRSA: Methicillin-resistant Staphylococcus aureus; PCR: Polymerase chain reaction

\section{Acknowledgements}

The authors acknowledge the help and cooperation of patients and animal owners for providing samples. We also thank Kate Fox, DPhil, from Edanz Group (www.edanzediting.com/ac) for editing a draft of this manuscript.

\section{Funding}

This work was funded by the University Grants Commission of Bangladesh, UGC Bhaban, Agargaon, Dhaka-1207.

\section{Availability of data and materials}

All data generated or analyzed during this study are included in this manuscript. The raw data can be found in Additional files 1 and 2, respectively.

\section{Authors' contributions}

MMA designed the study. MMR, KBA, SMMR, AK and AH collected the specimens. MMR, KBA, SMMR, AH, AK, and MR performed the experiments. MMR, MR, NM and AKMAR drafted the manuscript. MMA, AKMAR, and NM critically revised the manuscript. All authors have read and approved the manuscript.

\section{Ethics approval and consent to participate}

Informed verbal and written consent for the collection of samples was obtained from all patients and the owners of the animals (verbal consent only). The study protocol was approved by the Ethics Committee of Mymensingh Medical College and Bangladesh Agricultural University, Bangladesh.

Consent for publication

Not applicable.

\section{Competing interests}

The authors declare that they have no competing interests.

\section{Publisher's Note}

Springer Nature remains neutral with regard to jurisdictional claims in published maps and institutional affiliations.

\section{Author details}

${ }^{1}$ Department of Medicine, Faculty of Veterinary Science, Bangladesh Agricultural University, Mymensingh 2202, Bangladesh. ${ }^{2}$ Department of Microbiology \& Hygiene, Faculty of Veterinary Science, Bangladesh Agricultural University, Mymensingh 2202, Bangladesh. ${ }^{3}$ Department of Microbiology, Mymensingh Medical College, Mymensingh, Bangladesh. ${ }^{4}$ Veterinary Teaching Hospital, Joint Faculty of Veterinary Medicine, Kagoshima University, Kagoshima, Japan.

Received: 5 March 2018 Accepted: 12 September 2018

Published online: 03 October 2018

\section{References}

1. Barber M, Rozwadowska-Dowzenko M. Infection by penicillin-resistant Staphylococci. Lancet. 1948;252:641-4.

2. Barber M. Methicillin-resistant staphylococci. J Clin Pathol. 1961;14:385-94.

3. Boucher HW, Corey GR. Epidemiology of methicillin-resistant Staphylococcus aureus. Clin Infect Dis. 2008:46:S344-9.

4. Knox J, Uhlemann AC, Lowy FD. Staphylococcus aureus infections: transmission within households and the community. Trends Microbiol. 2015 23:437-44. 
5. Khan A, Wilson B, Gould IM. Current and future treatment options for communityassociated MRSA infection. Expert Opin Pharmacother. 2018;19:457-70.

6. Holmes MA, Zadoks RN. Methicillin resistant $S$. aureus in human and bovine mastitis. J Mammary Gland Biol. 2011:16:373-82.

7. Chambers HF. Methicillin resistance in staphylococci: molecular and biochemical basis and clinical implications. Clin Microbiol Rev. 1997;10:781-91.

8. Ray P, Gautam V, Singh R. Meticillin-resistant Staphylococcus aureus (MRSA) in developing and developed countries: implications and solutions. Regional Health Forum. 2011;15:74-82.

9. Lewis HC, Mølbak K, Reese C, Aarestrup FM, Selchau M, Sørum M, Skov RL. Pigs as source of methicillin-resistant Staphylococcus aureus CC398 infections in humans Denmark. Emerg Infect Dis. 2008;14:1383.

10. Cuny C, Wieler LH, Witte W. Livestock-associated MRSA: the impact on humans. Antibiotics. 2015;6:521-43.

11. Pexara A, Solomakos N, Govaris A. Prevalence of methicillin-resistant Staphylococcus aureus in milk and dairy products. J Hell Vet Med Soc. 2013;64:17-34.

12. Juhász-Kaszanyitzky É, Jánosi S, Somogyi P, Dán Á, van der Graaf van Bloois L, Van Duijkeren E, Wagenaar JA. MRSA transmission between cows and humans. Emerg Infect Dis. 2007;13:630-2.

13. Ferreira JP, Anderson KL, Correa MT, Lyman R, Ruffin F, Reller LB, Fowler VG Jr. Transmission of MRSA between companion animals and infected human patients presenting to outpatient medical care facilities. PLoS One. 2011;6:e26978.

14. Weese JS, Archambault M, Willey BM, Hearn P, Kreiswirth BN, Said-Salim B, McGeer A, Likhoshvay Y, Prescott JF, Low DE. Methicillin-resistant Staphylococcus aureus in horses and horse personnel, 2000-2002. Emerg Infect Dis. 2005;11:430-5.

15. Bramble M, Morris D, Tolomeo P, Lautenbach E. Potential role of pet animals in household transmission of methicillin-resistant Staphylococcus aureus: a narrative review. Vector Borne Zoonotic Dis. 2011;11:617-20.

16. Jevons MP, Coe AW, Parker MT. Methicillin resistance in staphylococci. Lancet. 1963;281:904-7.

17. Foster T. Staphylococcus. In: Baron S. (edt), Medical Microbiology, 4th ed. Chapter 12; 1996. Available from: http://www.ncbi.nlm.nih.gov/books/NBK8448.

18. Mehndiratta PL, Bhalla P. Use of antibiotics in animal agriculture \& emergence of methicillin-resistant Staphylococcus aureus (MRSA) clones: need to assess the impact on public health. Indian J Med Res. 2014;140:339-44.

19. Hiramatsu K, Cui L, Kuroda M, Ito T. The emergence and evolution of methicillin-resistant Staphylococcus aureus. Trends Microbiol. 2001;9:486-93.

20. deJonge BL, Tomasz A. Abnormal peptidoglycan produced in a methicillinresistant strain of Staphylococcus aureus grown in the presence of methicillin: functional role for penicillin-binding protein 2A in cell wall synthesis. Antimicrob Agents Ch. 1993;37:342-6.

21. Utsui YU, Yokota TA. Role of an altered penicillin-binding protein in methicillin-and cephem-resistant Staphylococcus aureus. Antimicrob Ag Ch. 1985;28:397-403.

22. Song MD, Wachi M, Ishino F, Matsuhashi M. Evolution of an inducible penicillin-target protein in methicillin-resistant Staphylococcus aureus by gene fusion. FEBS Lett. 1987;221:167-71.

23. Ubukata K, Nonoguchi R, Song MD, Matsuhashi M, Konno M. Homology of mecA gene in methicillin-resistant Staphylococcus haemolyticus and Staphylococcus simulans to that of Staphylococcus aureus. Antimicrob Ag Ch. 1990;34:170-2

24. Khan AH, Shamsuzzaman AKM, Paul SK, Alam MM, Mahmud MC. Antimicrobial susceptibility and coagulase typing of MRSA strains at Mymensingh medical college. Bangladesh J Med Microbiol. 2007;1:56-60.

25. Habibullah A, Rahman AM, Haydar MR, Nazir KH, Rahman MT. Prevalence and molecular detection of methicillin-resistant Staphylococcus Aureus from dogs and cats in Dhaka City. Bangl J Vet Med. 2017;15:51-7.

26. Quinn PJ, Markey BK, Bryan K, Leonard FC, Carter ME, Donnelly WJ. Veterinary microbiology and microbial disease. 1st ed. Chichester, West Sussex: Wiley-Blackwell; 2002.

27. Fang $H$, Hedin G. Rapid screening and identification of methicillin-resistant Staphylococcus aureus from clinical samples by selective-broth and real-time PCR assay. J Clin Microbiol. 2003:41:2894-9.

28. Zhang K, Conly J, inventors; UTI LP, assignee. Multiplex PCR Assay For Identification of USA300 and USA400 Community-Associated Methicillin Resistant Staphylococcal aureus Strains. U. S. patent application US 2009: 12/061-847.

29. Kluytmans J, VanBelkum A, Verbrugh H. Nasal carriage of Staphylococcus aureus: epidemiology, underlying mechanisms, and associated risks. Clin Microbiol Rev. 1997;10:505-20.
30. Loeffler A, Boag AK, Sung J, Lindsay JA, Guardabassi L, Dalsgaard A, Smith H, Stevens KB, Lloyd DH. Prevalence of methicillin-resistant Staphylococcus aureus among staff and pets in a small animal referral hospital in the UK. J Antimicrob Chemoth. 2005:5:692-7.

31. Loeffler A, Pfeiffer DU, Lindsay JA, Magalhaes RS, Lloyd DH. Prevalence of and risk factors for MRSA carriage in companion animals: a survey of dogs, cats and horses. Epidemiol Infect. 2011;139:1019-28.

32. Tarazi YH, Almajali AM, Ababneh MM, Ahmed HS, Jaran AS. Molecular study on methicillin-resistant Staphylococcus aureus strains isolated from dogs and associated personnel in Jordan. Asian Pac J Trop Biomed. 2015;5:902-8.

33. Grönthal $T$, Ollilainen $M$, Eklund M, Piiparinen $H$, Gindonis V, Junnila J, Saijonmaa-Koulumies L, Liimatainen R, Rantala M. Epidemiology of methicillin resistant Staphylococcus pseudintermedius in guide dogs in Finland. Acta Vet Scand. 2015;57:37.

34. Haenni M, Châtre P, Dupieux C, Métayer V, Bes M, Madec JY, Laurent F. Molecular epidemiology of methicillin-resistant Staphylococcus aureus in horses, cats and dogs over a 5-year period in France. Front Microbiol. 2017;8:2493.

35. Moodley A, Stegger M, Bagcigil AF, Baptiste KE, Loeffler A, Lloyd DH, Williams NJ, Leonard N, Abbott Y, Skov R, Guardabassi L. Spa typing of methicillin-resistant Staphylococcus aureus isolated from domestic animals and veterinary staff in the UK and Ireland. J Antimicrob Chemoth. 2006;58: $1118-23$.

36. Nienhoff U, Kadlec K, Chaberny IF, Verspohl J, Gerlach GF, Schwarz S, Simon D, Nolte I. Transmission of methicillin-resistant Staphylococcus aureus strains between humans and dogs: two case reports. J Antimicrob Chemoth. 2009; 64:660-2.

37. Haenni M, Saras E, Châtre P, Médaille C, Bes M, Madec JY, Laurent F. A USA300 variant and other human-related methicillin-resistant Staphylococcus aureus strains infecting cats and dogs in France. J AntimicrobChemoth. 2011;67:326-9.

38. Axon JE, Carrick JB, Barton MD, Collins NM, Russell CM, Kiehne J, Coombs G. Methicillin-resistant Staphylococcus aureus in a population of horses in Australia. Aust Vet J. 2011;89:221-5.

39. Walther B, Wieler LH, Friedrich AW, Hanssen AM, Kohn B, Brunnberg L, Lübke-Becker A. Methicillin-resistant Staphylococcus aureus (MRSA) isolated from small and exotic animals at a university hospital during routine microbiological examinations. Vet Microbiol. 2008;127:171-8.

40. Roess AA, Winch PJ, Ali NA, Akhter A, Afroz D, El Arifeen S, Darmstadt GL, Baqui AH. Bangladesh PROJAHNMO Study Group. Animal husbandry practices in rural Bangladesh: potential risk factors for antimicrobial drug resistance and emerging diseases. Am J Trop Med Hyg 2013; 89:965-970,

41. Schwaber MJ, Venkataraman L, DeGirolami PC, Gramatikova A, Perl TM, Sakoulas G, Wright SBB, Carmeli Y, Gold HS. Clinical implications of varying degrees of vancomycin susceptilibity in methicillin-resistant Staphylococcus aureus bacteremia. Emerg Infect Dis. 2003;9:657-64.

42. de Sousa MA. Bridges from hospitals to the laboratory: genetic portraits of methicillin-resistant Staphylococcus aureus clones. FEMS Immunol Med Microbiol. 2004;40:101-11.

43. Jinnah F, Chowdhury K, Begum J, Sohail M, Rahman T, Ahmed S, Rumi AK, Morshed MG, Huq F. Multiresistant Staphylococcus aureus isolated from the wound of diabetic patients. J Infect Dis Antimicrob Ag. 1998;15:15-8.

44. Sachdev D, Amladi S, Natraj G, Baveja S, Kharkar V, Mahajan S, Khopkar U. An outbreak of methicillin-resistant Staphylococcus aureus (MRSA) infection in dermatology indoor patients. Indian J Dermatol Venereol Leprol. 2003;69:377-80.

45. Alam MM, Uddin MS, Kobayashi N, Ahmed MU. Detection of methicillin-resistant Staphylococcus aureus (MRSA) from animal and human origin in Bangladesh by polymerase chain reaction. Bangladesh J Vet Med. 2011;9:161-6.

46. Biswas M, Roy DN, Tajmim A, Rajib SS, Hossain M, Farzana F, Yasmen N. Prescription antibiotics for outpatients in Bangladesh: a cross-sectional health survey conducted in three cities. Ann Clin Microbiol Abtimicrob. 2014;13:15.

47. Schmitz FJ, Sadurski R, Kray A, Boos M, Geisel R, Köhrer K, Verhoef J, Fluit AC Prevalence of macrolide-resistance genes in Staphylococcus aureus and Enterococcus faecium isolates from 24 European university hospitals. J Antimicrob Chemother. 2000;45:891-4.

48. Silva NC, Guimarães FF, Manzi MP, Júnior AF, Gómez-Sanz E, Gómez P, Langoni H, Rall VL, Torres C. Methicillin-resistant Staphylococcus aureus of lineage ST398 as cause of mastitis in cows. Lett Appl Microbiol. 2014;59: $665-9$. 